\title{
Carl Koller Gold Medal Award to Paolo Busoni at the Silver Anniversary ESRA Annual Congress, Monte Carlo, Monaco, September 6-9, 2006
}

\author{
André van Zundert, M.D., Ph.D., F.R.C.A.
}

$\mathbf{T}$ he European Society of Regional Anaesthesia and Pain Therapy (ESRA) instituted the Carl Koller Award in 1984, one hundred years after Carl Koller administered cocaine around the eye to achieve regional anesthesia. It is the tradition of ESRA that this award is given to anesthesiologists who have devoted their life to the practice, teaching, and promotion of regional anesthesia; and who have used their knowledge to further regional techniques. The recipient of the 2006 Carl Koller Award, at the occasion of ESRA's Silver Anniversary of the Annual Congress, is Professor Paolo Busoni, from Firenze, Italy.

Born, raised, and educated in the heart of one of Europe's most beautiful areas, Tuscany, Italy, Paolo Busoni graduated in medicine from the Medical School at Pisa University and finished his training in anesthesia at the same university in 1964. Early in his career Paolo realized the importance of neural blockades for anesthesia and pain treatment in neonates and children, his main field of interest. Paolo's contribution to the practice, research, and development of new block techniques made him one of the foremost pediatric anesthesiologists in the world. He has published numerous papers and book chapters, and served as an editorial member of several medical journals. Paolo Busoni was also actively involved in multiple ESRA activities in its early years and contributed greatly to the success of ESRA. He organized the first Italian ESRA meeting in 1982 and served as an ESRA Board Member from

From the Catharina Hospital-Brabant Medical School, Eindhoven, The Netherlands.

Accepted for publication November 27, 2006.

Reprint requests: André van Zundert, M.D., Ph.D., F.R.C.A., Catharina Hospital-Brabant Medical School, Eindhoven, The Netherlands. E-mail: zundert@iae.nl

(C) 2007 by the American Society of Regional Anesthesia and Pain Medicine.

1098-7339/07/3206-0001\$32.00/0

doi:10.1016/j.rapm.2007.10.001

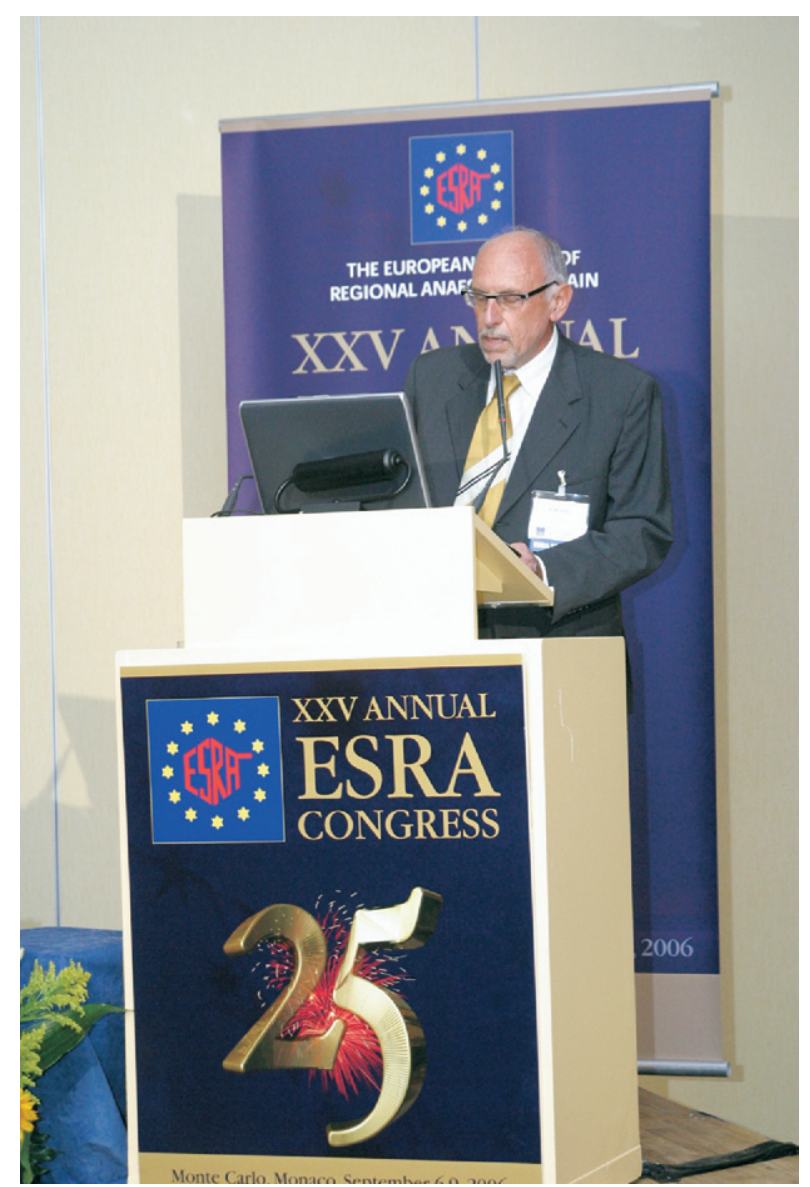

Fig 1. Paolo Busoni giving the 2006 ESRA Carl Koller Award Lecture in Monte Carlo, Monaco.

1992-1996. There was no greater pleasure and honor for many anesthesiologists who practice pediatric regional anesthesia, than coming to Florence and practicing nerve blocks under Paolo's supervision.

The following is a translated summary of Paolo Busoni's Koller Award lecture (Fig 1), "Why Is It Difficult to Control Pain in Children?" 